CASE REPORT

\title{
Takotsubo Stress Syndrome and Intracoronary Thromboembolic Occlusion: Fact or Myth?
}

\section{Stefan Peters*}

\section{St. Elisabeth Hospital Salzgitter, Germany}

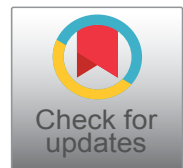

*Corresponding author: Stefan Peter, St. Elisabeth Hospital Salzgitter, Liebenhaller Str. 20, 38259 Salzgitter, Germany

For a long period of time there has been a controversy as to whether takotsubo syndrome is related to intracoronary thromboembolic occlusions.

\section{Methodology and Rationale}

No significant alterations have been seen in thrombophilic factors in takotsubo syndrome on serology [1] and no plaque rupture has been noted on intravascular ultrasound [2].

However, Pawlowski, et al. described vulnerable plaque surface, platelet activity and subsequent thrombus formation in virtual histology intravascular ultrasound evaluation of the left anterior descending coronary artery in slight or non-significant lesions [3].

In fact, on coronary angiography of the left anterior descending coronary artery, non-significant lesions has been seen in many cases with takotsubo syndrome characterized by left ventricular apical ballooning.

In many catheter laboratories left ventricular angiography is not performed in cases with ST-segment elevation. The correlation of significant findings in coronary vessels and the function of the left ventricle cannot be reliably correlated. Echocardiography can help in these cases directly before or after coronary angiography.

In cases of ST segment depression and coronary angiography after a maximum of 72 hours subsequent thrombus formation might no longer be detectable and transient thromboembolic occlusion can be missed.

\section{Results}

A few case reports found an association between left ventricular apical ballooning and transient thromboembolic occlusion in myocardial bridging of the mid-por- tion left anterior descending coronary artery [4].

In two additional, so far unpublished case reports distal or mid-portion thromboembolic occlusion of the left anterior descending coronary artery and the first diagonal branch were described. Both cases had a tragic outcome-either due to myocardial perforation or disseminated intravascular coagulation.

\section{Discussion}

Thromboembolic occlusion of the left anterior descending coronary artery (and its diagonal branch) may exist in takotsubo syndrome as reported in a few case reports. Also highly controversial are the findings of intravascular ultrasound of the left anterior descending coronary artery $[2,3]$ either with or without vulnerable plaque surface, altered platelet activity and subsequent thrombus formation.

\section{Conclusion}

Transient thromboembolic occlusion may be added to different causes of takotsubo syndrome in a few cases, although it should be clearly stated that a few cases cannot be used as a generalization. Myocardial bridging [5], spasm [6] or catecholamine (stress) mediated causes are well known and described in the literature.

\section{References}

1. Cecchi E, Parodi G, Fatucchi S, Angelotti P, Giglioli C, et al. (2016) Prevalence of thrombophilic disorders in takotsubo patients: The (ThROmbophylia in TAkotsubo cardiomyopathy) TROTA study. Clin Res Cardiol 105: 717-726.

2. Haghi D, Rohm S, Hamm K, Harder N, Suselbeck T, et al. (2010) Takotsubo cardiomyopathy is not due to plaque rupture: An intravascular ultrasound study. Clin Cardiol 33: 307-310.

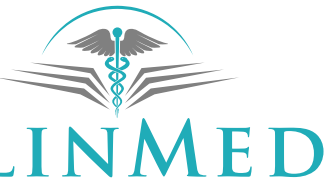

NTERNATIONAL LIBRARY

Citation: Peters S (2018) Takotsubo Stress Syndrome and Intracoronary Thromboembolic Occlusion: Fact or Myth?. Int J Clin Cardiol 5:126. doi.org/10.23937/2378-2951/1410126

Accepted: October 22, 2018; Published: October 24, 2018

Copyright: (C) 2018 Peters S. This is an open-access article distributed under the terms of the Creative Commons Attribution License, which permits unrestricted use, distribution, and reproduction in any medium, provided the original author and source are credited. 
3. Pawlowski T, Mintz GS, Kulawik T, Gil RJ (2010) Virtual histology intravascular unltrasound evaluation of the left anterior descending coronary artery in patients with transient left ventricular ballooning syndrome. Kardiol Pol 68: 1093-1098.

4. Peters S (2016) Subsequent thrombus formation in a patient with apical ballooning. In J Cardiol 222: 421.
5. Migliori F, Maffei E, Perazzolo Marra M, Bilato C, Napodano $M$, et al. (2013) LAD coronary myocardial bridging and apical ballooning. JACC Cardiovasc Imaging 6: 32-41.

6. Ando G, Trio O, de Gregorio C (2016) Coronary spasm and myocardial bridging: An elusive pathophysiological mechanism leading to apical ballooning syndrome? Eur Heart $\mathrm{J}$ Acute Cardiovasc Care 5: 501-504. 